\title{
Sonic Hedgehog Pathway Activation Is Induced by Acute Brain Injury and Regulated by Injury-Related Inflammation
}

\author{
Nduka M. Amankulor, ${ }^{1,2 \star}$ Dolores Hambardzumyan, ${ }^{1,3 \star}$ Stephanie M. Pyonteck, ${ }^{1,7}$ Oren J. Becher, ${ }^{1,4}$ Johanna A. Joyce, ${ }^{1}$ \\ and Eric C. Holland $1,3,5,6$ \\ Departments of ${ }^{1}$ Cancer Biology and Genetics and ${ }^{2}$ Neurosurgery, Yale University School of Medicine, New Haven, Connecticut 06510, ${ }^{3}$ The Brain Tumor \\ Center, Departments of ${ }^{4}$ Pediatrics and ${ }^{5}$ Surgery, and ${ }^{6}$ Section of Neurosurgery, Memorial Sloan-Kettering Cancer Center, New York, New York 10021 , and \\ ${ }^{7}$ Weill Cornell Graduate School of Medical Sciences, Cornell University, New York, New York 10065
}

The adult mammalian brain responds to injury by activating a program of cell proliferation during which many oligodendrocyte precursors, microglia, and some astrocytes proliferate. Another common response to brain injury is the induction of reactive gliosis, a process whereby dormant astrocytes undergo morphological changes and alter their transcriptional profiles. Although brain injury-induced reactive gliosis is concurrent with the proliferation of surrounding cells, a functional relationship between reactive gliosis and this cell proliferation has not been clearly demonstrated. Here, we show that the mitogen sonic hedgehog $(\mathrm{SHH})$ is produced in reactive astrocytes after injury to the cerebral cortex and participates in regulating the proliferation of Olig2-expressing $\left(0 \mathrm{lig} 2^{+}\right)$cells after brain injury. Using a cortical freeze injury to induce reactive gliosis in a Gli-luciferase reporter mouse, we show that the SHH pathway is maximally active $3 \mathrm{~d}$ after brain injury and returns to baseline levels by $14 \mathrm{~d}$. SHH expression parallels Gli activation and localizes to glial fibrillary acidic protein-expressing reactive astrocytes. Inhibition of the SHH pathway with cyclopamine blocks the Gli response and significantly reduces both the proliferating and overall number of Olig2 ${ }^{+}$cells in the injured cortex. To provide mechanistic insight into SHH pathway activation in astrocytes, we show that proinflammatory stimuli activate SHH-expressing reactive astrocytes, whereas inhibition of inflammation-induced reactive gliosis by macrophage depletion abolishes SHH activation after brain injury and dampens cell proliferation after injury. Our data describes a unique reactive astrocyte-based, SHH-expressing niche formed in response to injury and inflammation that regulates the proliferation of Olig ${ }^{+}$cells.

\section{Introduction}

Injury to neural tissue results in the establishment of a complex microenvironment composed of astrocytes, neurons, immune cells, proliferating and nonproliferating oligodendrocytes, dying cells, and other cell types (Raghupathi et al., 2000; Hampton et al., 2004). The temporal pattern of acute events in the injured brain microenvironment is well studied: inflammatory cytokinesecreting microglia appear within a few hours after the insult, whereas astrocytes, proliferating oligodendrocytes, and new vascular channels are seen by $24-72 \mathrm{~h}$ (Hampton et al., 2004). The role of proliferating cells in the context of cerebral cortical injury remains to be fully elucidated, but, in certain diseases, including multiple sclerosis, Olig2-expressing (Olig2 ${ }^{+}$) precursor populations appear to contribute to the remyelination of injured axons (Talbott et al., 2005).

Certain injury-responsive astrocytes are characterized by increased expression of the intermediate filament glial fibrillary

\footnotetext{
Received May 28, 2009; accepted June 24, 2009

N.M.A. and E.C.H. were supported by Department of Defense Traumatic Brain Injury Award PT073581, and E.C.H. and J.A.J. were supported by National Institutes of Health Tumor Microenvironment Network Grant CA 126518. We acknowledge Robert Finney and Mesruh Turkekul for their technical assistance.

${ }^{*}$ N.M.A. and D.H. contributed equally to this work.

Correspondence should be addressed to Dr. Eric C. Holland, Section of Neurosurgery, Memorial Sloan-Kettering Cancer Center, 1275 York Avenue, New York, NY 10021. E-mail: hollande@mskcc.org. D0I:10.1523/JNEUROSCI.2500-09.2009

Copyright $\odot 2009$ Society for Neuroscience $\quad 0270-6474 / 09 / 2910299-10 \$ 15.00 / 0$
}

acidic protein (GFAP), among other molecular alterations, and are termed "reactive" astrocytes (Höke and Silver, 1994). Reactive astrocytes are best known as the primary component of the glial scar and for their ability to inhibit axonal regeneration, but one outstanding question is whether astrocytes contribute to the mitogenic capacity of the injured CNS (White and Jakeman, 2008).

We showed recently that reactive astrocytes respond to gliomagenesis by expressing sonic hedgehog (SHH) (Becher et al., 2008), but the functional consequences of astrocyte-derived SHH remain unclear. SHH displays both morphogenic and mitogenic properties during development. In particular, SHH expression drives the expression of the basic helix-loop-helix transcription factor Olig2 and induces the proliferation of Olig2-expressing cells in the developing mammalian ventral neural tube. SHH has been studied mainly in the context of development, but there is increasing evidence to suggest that the mitogenic properties of $\mathrm{SHH}$ are retained during adulthood, in which $\mathrm{SHH}$ promotes oncogenesis or tissue repair in different organs. In the mammalian brain, in which injury-related cell proliferation is transient, knowledge of factors that promote cell proliferation might be clinically useful, especially in the setting of traumatic brain injury, in which cell loss is an obstacle to recovery.

Based on our previous work on the role of SHH during gliomagenesis, we hypothesized that $\mathrm{SHH}$ activity in gliomas is caused by tumor-induced injury to surrounding brain. Because 
reactive astrocytes are present during most types of brain injury (including brain tumors), we surmised that SHH pathway activation in reactive astrocytes occurs during non-neoplastic brain injury and that $\mathrm{SHH}$ expression in reactive astrocytes might play a role in promoting cell proliferation during brain injury, analogous to its role during certain types of brain tumors.

In this study, we use a mouse model to demonstrate activation of the SHH-Gli signaling pathway and to describe the temporal pattern of its activation during acute brain injury. To characterize the mechanisms underlying $\mathrm{SHH}$ induction in vivo, we interrogated the role of inflammation in the formation of reactive astrocytes during injury and provide unique evidence that in vivo macrophage-mediated inflammatory processes and proinflammatory cytokine production is required for the induction of reactive astrocytes and, consequently, for $\mathrm{SHH}$ expression during brain injury.

\section{Materials and Methods}

Mice. All experiments were performed in accordance to the Institutional Animal Care and Use Committee guidelines at Memorial SloanKettering Cancer Center. Generation of the Gli-luciferase (Gli-Luc) mice (Becher et al., 2008) and CD11b-diphtheria toxin receptor (DTR) mice (Duffield et al., 2005) has been described previously. CD11bDTR mice were the kind gift from Dr. Richard Lang (University of Cincinnati, Cincinnati, OH). Gli-Luc mice were used for all injury experiments except for macrophage ablation experiments. For macrophage depletion experiments, Gli-Luc/CD11b-DTR heterozygous mice were generated by crossing the $G l i-\mathrm{Luc}^{+/-}$mice with CD11b-DTR ${ }^{+/+}$mice. All offspring were imaged by bioluminescence (BLI) for luciferase, and only Gli-Luc-positive mice were used. Littermate controls were used for each experiment. For macrophage depletion experiments, $25 \mathrm{ng} / \mathrm{g}$ per mouse of diphtheria toxin (DT) (List Biologicals) solution $(3.3 \mu \mathrm{g} / \mathrm{ml}$ $\mathrm{H}_{2} \mathrm{O}$ ) was administered intraperitoneally daily for 4 consecutive days. Injuries were performed on day 2 of treatment, and animals were killed on the third day after injury. For a subset of DT-treated mice, $10 \mathrm{ng}$ of the cytokine IL- $1 \beta$ was injected into the injured cortex immediately after injury. For cyclopamine treatment, four consecutive daily injections of cyclopamine $(25 \mathrm{mg} / \mathrm{kg}$ ) were given as described previously (Palma et al., 2005). Cyclopamine was a kind gift from Dale Gardner (United States Department of Agriculture). At least three mice per group were used for every experimental and control group.

Cortical freeze injury, lipopolysaccharide injection, and IL-1ß injection. This injury protocol was adapted from previously published procedures (Sun et al., 2004). This injury method combines a stab wound and freeze injury to induce significant injury in a focal region of brain. Briefly, animals were anesthetized with an intraperitoneal solution of ketamine/ xylazine and placed in a stereotactic frame (Stoelting). A midline incision was made, the skin was retracted laterally, and a small burr hole was drilled using the following coordinates: anteroposterior, $1.7 \mathrm{~mm}$ posterior to bregma; and lateral (right), $1 \mathrm{~mm}$ from midline. A 21.5 gauge needle was fixed unto the stereotactic device, precooled in liquid nitrogen for $30 \mathrm{~s}$, and then lowered $1 \mathrm{~mm}$ deep to the dural surface for $30 \mathrm{~s}$. The injury was repeated three times per animal at $1 \mathrm{~min}$ intervals.

For lipopolysaccharide (LPS) injections, LPS ( $1 \mu \mathrm{g}$ in $0.5 \mu \mathrm{l}$ of sterile saline) from Escherichia coli (055:B5 serotype; Sigma) or sterile saline alone was injected into the same cortical location as the freeze injury using a Hamilton syringe fastened to the stereotactic frame at a rate of 2 $\mu \mathrm{l} / \mathrm{s}$. Animals for LPS experiments were killed $3 \mathrm{~d}$ after injection. For IL- $1 \beta$ injections, $10 \mathrm{ng}$ of mouse recombinant IL- $1 \beta$ (Peprotech) in $1 \mu \mathrm{l}$ of sterile water was injected in the same way as the LPS injections.

Immunohistochemistry and histology. Mice were killed after BLI imaging with a lethal dose of ketamine/xylazine. Brains were removed and postfixed in $4 \%$ paraformaldehyde for $2-4 \mathrm{~h}$ and then transferred to a $30 \%$ sucrose solution $24 \mathrm{~h}$ for cryoprotection. Brains were then sliced into two coronal sections at the point of injury, placed in O.C.T medium (Sakura), and frozen on dry ice. Coronal sections, $8 \mu \mathrm{m}$, were used for all histological studies. All immunohistochemical procedures were performed as described previously (Becher et al., 2008). The following antibodies were used at the stated dilutions: rat monoclonal anti-bromodeoxyuridine (BrdU), 1:100 (Abcam); rat anti-mouse anti-CD11b, 1:100 (BD Pharmingen); rabbit polyclonal anti-cleaved caspase 3, 1:100 (Cell Signaling Technology); rabbit polyclonal anti-Iba1, 1:1000 (Wako Pure Chemicals); rabbit polyclonal anti-GFAP, 1:1000 (Dako); mouse monoclonal anti-GFAP, 1:200 (Dako); rabbit polyclonal anti-Olig2, 1:100 (Millipore Bioscience Research Reagents); and mouse monoclonal anti-proliferating cell nuclear antigen (PCNA), 1:100 (Dako).

Flow cytometric analysis. Peritoneal cells were isolated by peritoneal lavage with a total of $10 \mathrm{ml}$ of PBS. Mice were anesthetized for imaging and then given a lethal dose of ketamine/xylazine. A $20 \mathrm{cc}$ syringe mounted with an 18 gauge needle was filled with $10 \mathrm{cc}$ of ice-cold PBS, and the entire volume was injected into the mouse peritoneum. The abdomen was then massaged, allowing efflux of the injected PBS into a 15 $\mathrm{ml}$ of polypropylene canonical tube. The fluid was centrifuged at 1000 rpm for $1 \mathrm{~min}$. Cells were resuspended in fluorescence-activated cell sorting (FACS) buffer [1\% protease-free, IgG-free bovine serum albumin (Jackson ImmunoResearch) in PBS] and incubated with rat antimouse CD16/CD32 Fc Block (BD Pharmingen) for $15 \mathrm{~min}$ at $4^{\circ} \mathrm{C}$. For flow cytometric analysis, $1 \times 10^{5}$ cells were incubated with $1 \mu \mathrm{l}$ of fluorophore-conjugated antibody in a volume of $50 \mu \mathrm{l}$ for $20 \mathrm{~min}$ at $4^{\circ} \mathrm{C}$. The antibodies used were rat anti-Gr-1 FITC (BD Pharmingen) and rat anti-F4/80 PE (Serotec). The cells were then washed three times with FACS buffer and fixed in $4 \%$ paraformaldehyde before analysis. Cell samples for flow cytometry were analyzed on a BD LSRII instrument.

RNA isolation. An $\sim 1 \mathrm{~mm}^{3}$ region of injured cortex (or contralateral brain) was dissected out from the whole brain on a cooled cutting board. The brain samples were placed in $1 \mathrm{ml}$ of Trizol reagent (Invitrogen) and homogenized, and RNA was extracted according to the protocol of the manufacturer.

Quantification of $m R N A$ by reverse transcription-PCR and real-time quantitative PCR. cDNA was synthesized from $1 \mu \mathrm{g}$ of purified total RNA isolated from a $1 \mathrm{~mm}^{3}$ region of the injured cortex by using the SuperScript III First-Strand Synthesis System for reverse transcription (RT)PCR (Invitrogen), following the protocols of the manufacturer. Total RNA from the identical region of the contralateral cortex was used as a control. Real-time PCR was performed using the 7900HT Fast Real Time PCR System (Applied Biosystems). Each sample was analyzed in triplicate. IL-1 $\beta$ (Mm00434228), IL-6 (Mm00446190), and tumor necrosis factor- $\alpha$ (TNF- $\alpha)($ Mm00443258) primers were obtained from Applied Biosystems. The SHH primer has been described previously (Russell et al., 2007).

In situ hybridization. The $\mathrm{SHH}$ in situ probe was a kind gift from Kathryn Anderson (Memorial Sloan-Kettering Cancer Center, New York, NY), and hybridization was conducted as described previously (Eggenschwiler and Anderson, 2000).

Mouse bioluminescence imaging and analysis. Mice were given a lethal dose of a ketamine/xylazine solution, followed by a retro-orbital injection of luciferin $\left(75 \mathrm{mg} / \mathrm{kg}\right.$ solution with $30 \mathrm{mg}$ luciferin $\left./ \mathrm{ml} \mathrm{H}_{2} \mathrm{O}\right)$ into the right eye as a bolus injection. The usual volume injected ranged from 50 to $100 \mu \mathrm{l}$. Luciferin was synthesized at the Memorial Sloan-Kettering Cancer Center core facility. Mice were decapitated $3 \mathrm{~min}$ after luciferin injection. Their brains were placed in one well of a six-well dish with $1 \mathrm{ml}$ of PBS and $3 \mathrm{mg}$ of luciferin, and images were acquired for $3 \mathrm{~min}$ in the IVIS 200 machine (Xenogen) at imaging level A. A 2 mm circular region of interest (ROI) was used to define the injury, and an identical area in the contralateral uninjured cortex of the same mouse was used as an internal control. All images were analyzed using the same maximum and minimum threshold parameters. A bioluminescence ratio was defined as the ratio of the BLI values from the ROI of the injured cortex to the uninjured cortex, and this ratio was used for all injury experiments.

Capture and quantification of immunohistochemistry photomicrographs. Immunofluorescence photomicrographs were taken on a Leica DMI 6000 microscope with a DFC 350FX digital camera; DAB and in situ histochemistry photomicrographs were taken on a Nikon E400 microscope fitted with a Nikon DS-SM camera. Quantification of positive cells was performed with the MetaMorph imaging system. For each experiment, images were captured from at least 24 different $20 \times$ photomicro- 


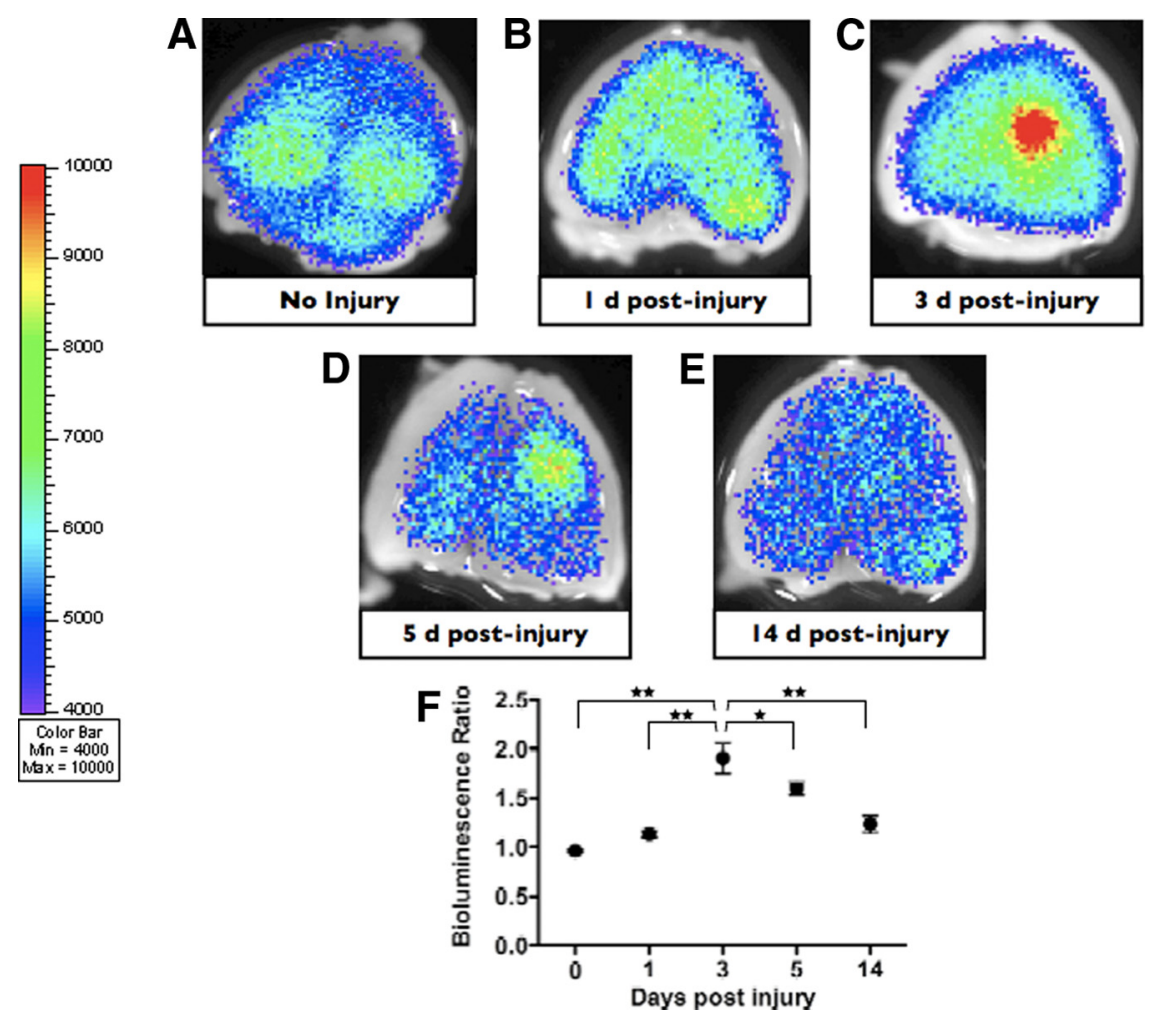

Figure 1. The Gli pathway is activated after a cortical freeze injury in the mouse brain. $\boldsymbol{A}-\boldsymbol{E}$, Gli bioluminescence imaging of an uninjured brain and brains imaged $1,3,5$, and $14 \mathrm{~d}$ after injury, respectively. A focal increase in BLI intensity was noted at 3 and $5 \mathrm{~d}$ after injury. $F$, Quantification and statistical analysis of the BLI intensity over the injury area compared with the identical area in the uninjured cortex of the same mouse.

graphs from at least three different animals. Four nonoverlapping $20 \times$ quadrants surrounding the injury per section were used for quantification. A color threshold was set by the operator, and only cells meeting this threshold were included.

Statistical analysis. Graphs were made using GraphPad Prism 4 (Graph Pad Software). Two-sided Student's tests and ANOVA were used for statistical testing. A coefficient of correlation $r^{2}$ and corresponding $p$ values were used to compare Gli-Luc BLI and PCNA immunostaining. In the figures, ${ }^{*} p<0.05,{ }^{* *} p<0.01$, and ${ }^{* * *} p<0.001$.

\section{Results}

The sonic hedgehog effector Gli is activated during a cortical freeze injury

We used a Gli-Luc transgenic reporter mouse containing eight contiguous Gli binding sites upstream of the firefly luciferase gene to study the potential activation of the SHH-Gli pathway during brain injury (Sasaki et al., 1997). To study Gli activation in injury, we used a cortical freeze injury, a method of injury that effectively combines a small stab wound with a freeze injury (Sun et al., 2004). After cortical injury, we compared the Gli-Luc bioluminescence output in the injured and uninjured cerebrum of brain-injured mice. Focal cortical injury in the frontoparietal cortex of Gli-Luc mice resulted in a highly reproducible pattern of Gli activation as determined by BLI. Uninjured mice had equal Gli-Luc BLI output in either cerebral hemisphere (Fig. $1 A, F$ ). At $24 \mathrm{~h}$ after cortical injury, there was a small and statistically insignificant increase in the BLI activity in the ipsilateral (injured) ortex compared with the contralateral (uninjured) side (Fig. 1B,F). At $72 \mathrm{~h}$ after the injury, however, we observed an increase in Gli activation that was significantly greater in the injured region compared with the contralateral cortex (approximately twofold increase compared with the uninjured cortex; $p<0.001$ ) (Fig.
$1 C, F)$. The increased BLI signal in the injury region was maintained at $5 \mathrm{~d}$ after cortical freeze injury $(\sim 1.6$-fold increase compared with uninjured cortex; $p<$ 0.001) (Fig. $1 D, F)$. However, by $14 \mathrm{~d}$ after brain injury, Gli-Luc BLI output was not significantly different between the two sides (Fig. 1E,F).

Sonic hedgehog is expressed by reactive astrocytes in the injured cerebral cortex The vast majority of Gli activation occurs in the context of canonical SHH pathway signaling, during which $\mathrm{SHH}$ binding of its receptor, Patched, results in a series of downstream events that ultimately results in Gli translocation to the nucleus and the transcription of $\mathrm{SHH}$ target genes (Stone et al., 1996). Our previous experiments in a mouse model of glioma showed that $\mathrm{SHH}$ expression was localized to GFAPexpressing reactive astrocytes within the tumor stroma (Becher et al., 2008). To determine whether the injury-induced GliLuc BLI increase (Fig. $1 C, D$ ) was a result of canonical $\mathrm{SHH}$ expression from reactive astrocytes, we performed SHH in situ hybridization of brains processed $3 \mathrm{~d}$ after brain injury. We observed robust expression of SHH mRNA at postinjury day 3, whereas the uninjured brain contained minimal SHH mRNA expression (Fig. $2 A, B$, respectively; black arrowheads indicated positively stained cells). We also used quantitative PCR to measure SHH levels in the injured cortex compared with the uninjured brain and found a twofold increase in SHH levels, consistent with our BLI experiments (data not shown). To identify the cells producing $\mathrm{SHH}$, we analyzed brains for $\mathrm{SHH}$ protein expression by immunostaining with an anti-SHH antibody. Consistent with the results from Gli-Luc BLI experiments, uninjured brains (Fig. 2C) and brains obtained at $24 \mathrm{~h}$ after injury (Fig. 2C) exhibited very low levels of $\mathrm{SHH}$ protein expression. In contrast, $\mathrm{SHH}$ expression was significantly increased in the injured brain $3 \mathrm{~d}$ after freeze injury (Fig. $2 C, 3 \mathrm{~d}$ after injury, magnified images shown in bottom panel) and was localized to GFAP-expressing reactive astrocytes. $\mathrm{SHH}$ protein expression returned to near baseline levels by $14 \mathrm{~d}$ after cortical brain injury (Fig. $2 C$, top rightmost panel).

\section{Cyclopamine abolishes brain injury-induced Gli activation}

During canonical SHH signaling, $\mathrm{SHH}$ is secreted and acts in an autocrine or paracrine manner on effector cells that use the Patched, Smoothened, and Gli proteins to transduce the $\mathrm{SHH}$ signal. One way to disconnect the $\mathrm{SHH}$ signal from its effector apparatus is to treat with cyclopamine, a small-molecule Veratrum alkaloid that inhibits $\mathrm{SHH}$ signaling by inhibiting the Smoothened receptor and interferes with $\mathrm{SHH}$ signal transduction in $\mathrm{SHH}$-responsive cells. We used this method to determine whether we could disrupt injury-induced $\mathrm{SHH}$ signaling in vivo. To do this, we pretreated animals with $25 \mathrm{mg} / \mathrm{kg}$ intraperitoneal cyclopamine or vehicle alone for $1 \mathrm{~d}$ before injury and then continued with daily injections for 3 more days, including the day of injury. Animals were killed on the third day after injury, when the SHH-Gli axis is maximally activated (Figs. 1, 2). Cyclopamine 

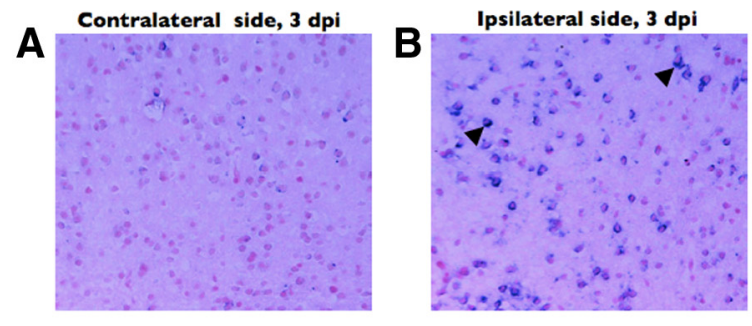

C
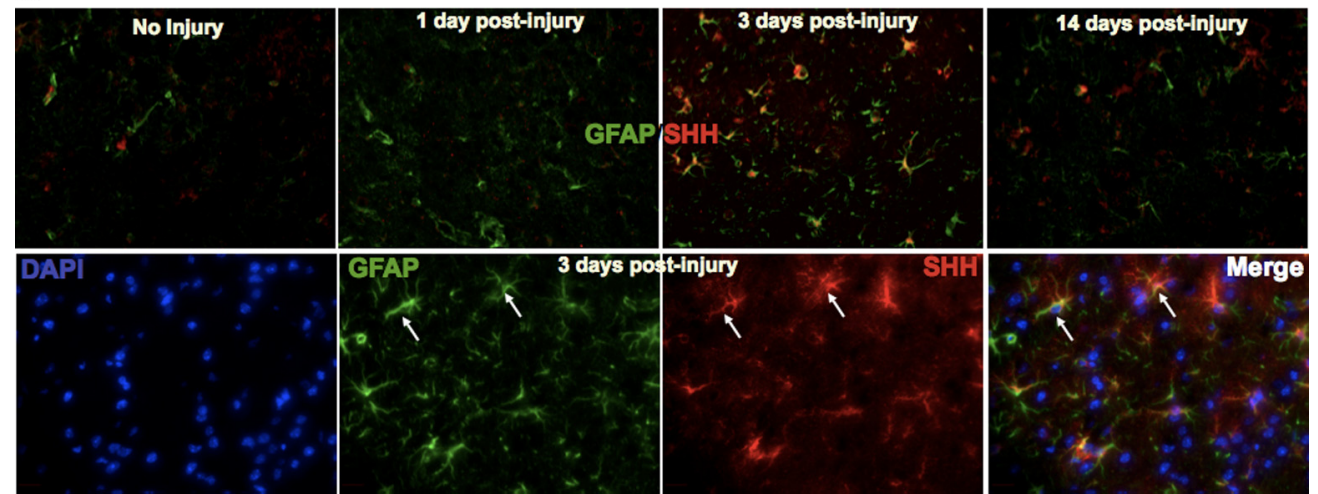

Figure 2. SHH is expressed in the mouse brain after brain injury. $A, B, I n$ situ hybridization for SHH in the uninjured contralateral hemisphere and injured brain, respectively. Black arrowheads indicate positively stained cells (blue) in the injured right cortex. C, Top, from left to right, SHH and GFAP double immunofluorescence from uninjured brain and brains processed after 1,3, and 14 d after injury, respectively. C, Bottom, from left to right, High-magnification immunofluorescence staining of a mouse brain at $3 \mathrm{~d}$ after injuring showing $4^{\prime}, 6^{\prime}$-diamidino-2-phenylindole (DAPI), GFAP, SHH, and a merged image, respectively. White arrows indicate astrocyte costaining for SHH and GFAP. Images in $\boldsymbol{A}, \boldsymbol{B}$, and $\boldsymbol{C}$ (top) were taken at $20 \times$ magnification. Images in $\boldsymbol{C}$ (bottom) were taken at $63 \times$ magnification. dpi, Days post-injury.

abrogated the injury-induced increase in the Gli signaling (Fig. 3C,D) compared with brain-injured animals receiving vehicle alone (Fig. $3 B$ ) or control animals receiving vehicle alone (Fig. $3 A$ ) in a statistically significant manner $(p<0.01)$.

Cyclopamine inhibits cellular proliferation after brain injury

The role of $\mathrm{SHH}$ in the specification and mitogenesis of certain cell populations in the developing neural tube (Incardona et al., 1998) and telencephalon (TekkiKessaris et al., 2001) has been clearly established. Moreover, SHH is important in the maintenance and proliferation of neural stem cells and transient amplifying cells, which then give rise to a variety of more differentiated cells in the stem cell regions of the adult brain (Ahn and Joyner, 2005). Given the ectopic activation of GliLuc and expression of $\mathrm{SHH}$ in the injured cortex, we wondered whether SHH activation was responsible for the proliferation of cells occurring during brain injury. We first observed that animals expressing higher levels of Gli-Luc in response to injury displayed a clear propensity toward increased cell proliferation in the injured cortex (Fig. $4 C)\left(r^{2}=\right.$ $0.558 ; p=0.0022$ ). Histological analysis of injured (vehicle treated) (Fig. 4A) versus injured brains after treatment with cyclopamine confirmed that inhibition of Gli activity was associated with a marked reduction in proliferating cells after brain injury (Fig. $4 B$, PCNA staining), which corresponded to a clear decrease in Gli-Luc BLI after cyclopamine treatment, as de-
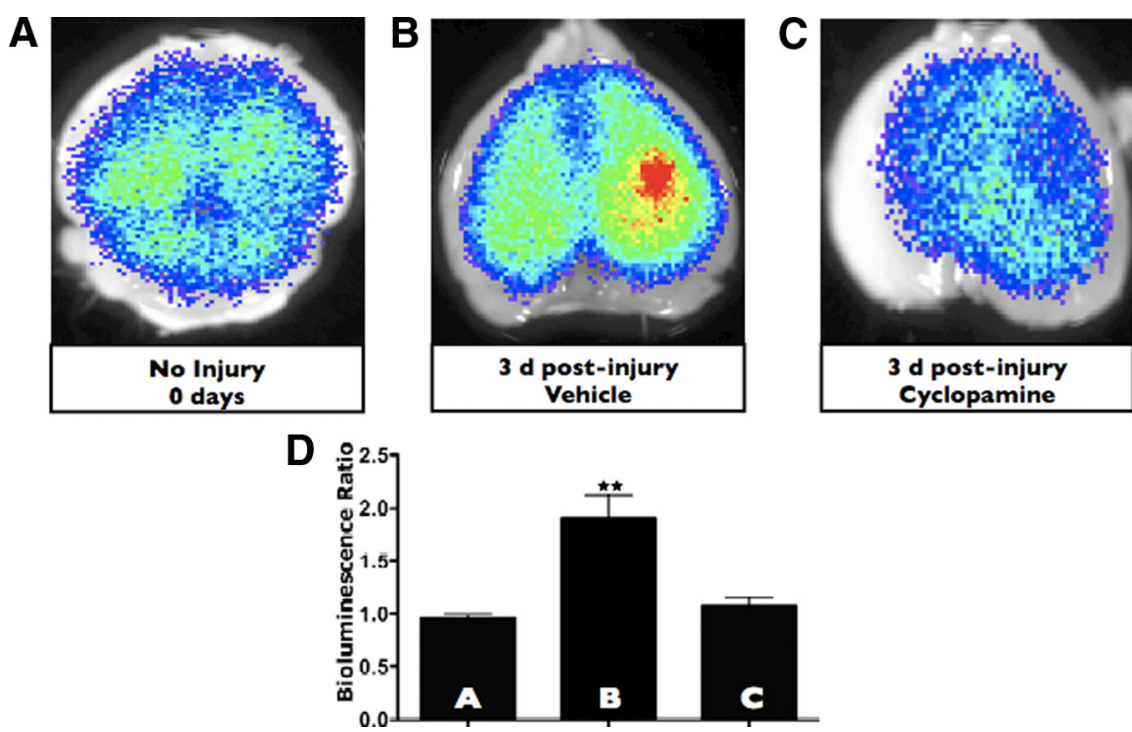

Figure 3. Cyclopamine disrupts Gli activation after brain injury. A-C, Gli-Luc bioluminescence was obtained in vehicle-treated and uninjured mice, vehicle-treated and injured mice ( $3 \mathrm{~d}$ after injury), and cyclopamine-treated and injured mice ( $3 \mathrm{~d}$ after injury). D, Quantification of Gli-Luc bioluminescence for $\boldsymbol{A}-\boldsymbol{C}$. Letters in the bar graph correspond to the BLI images. $p<0.01$ for vehicle-treated and injured mice compared with either uninjured or cyclopamine-treated mice.

scribed above, $3 \mathrm{~d}$ after brain injury (Fig. $4 B$, bottom inset). BrdU staining of adjacent sections was similar to PCNA immunohistochemistry, and cyclopamine treatment did not result in a significant change in the number of cleaved caspase-3 or terminal deoxynucleotidyl transferase-mediated biotinylated UTP nick end labeling staining (data not shown), suggesting that apoptotic mechanisms were not responsible for the lack of cell proliferation observed in cyclopamine-treated, brain-injured animals. 


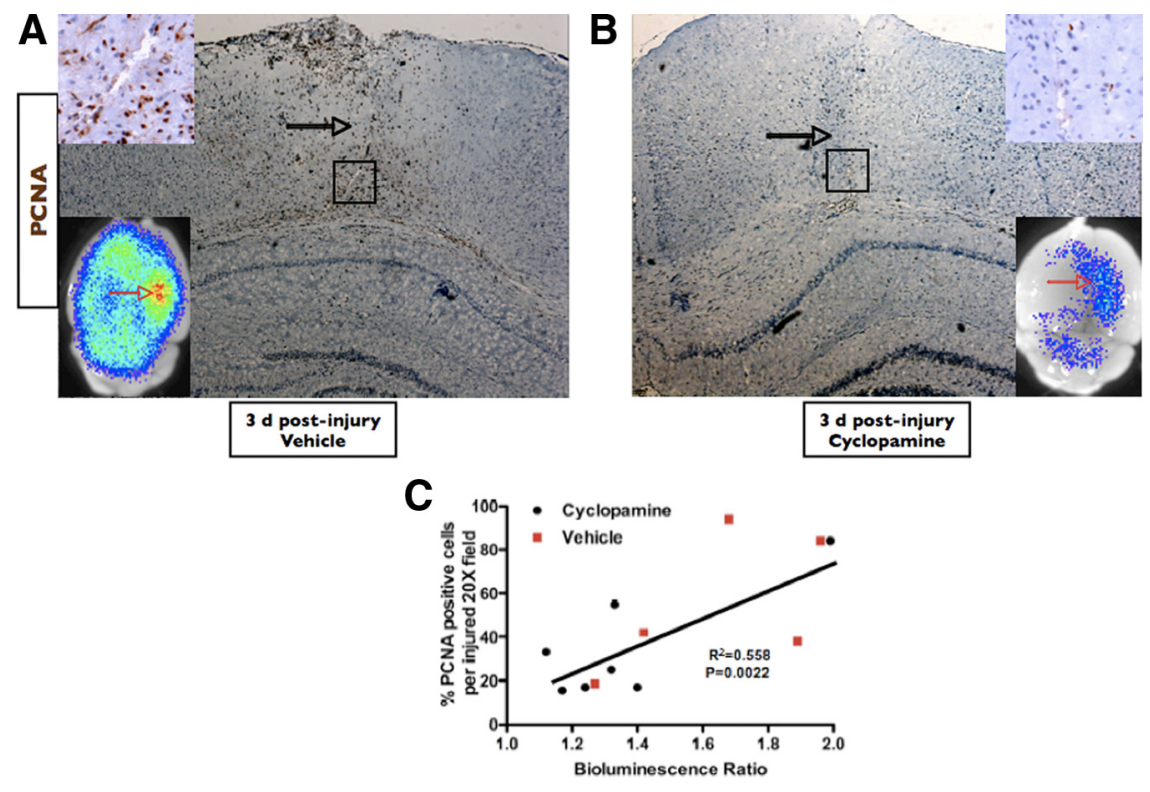

Figure 4. Cyclopamine reduces the proliferative capacity of injured brain. $A, B, P C N A$ and BLI of cyclopamine-treated and vehicle-treated brains at $3 \mathrm{~d}$ after injury, respectively. Open black arrows point to the needle tracks for each injury. Black boxes identify the area magnified in the top inset of each image. The bottom insets are BLI images of the brains that correspond to the immunohistochemistry micrograph. Open red arrows point to the area of injury for the BLI images. C, Simple linear regression showing a positive correlation $\left(r^{2}\right)$ between $\mathrm{Gli} B L \mathrm{l}$ intensity and PCNA expression in injured brains and the corresponding $p$ value. Both vehicle-treated (red squares; $n=5$ ) and cyclopamine-treated (black circles; $n=7$ ) mice were included in the regression analysis. $\boldsymbol{A}$ and $\boldsymbol{B}$ were taken under $5 \times$ magnification; inset PCNA images were taken under $40 \times$ magnification.
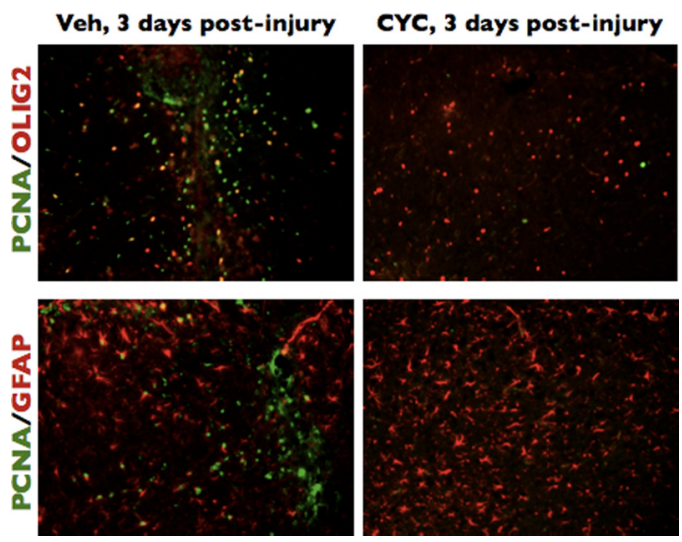

Figure 5. Cyclopamine preferentially reduces the number of proliferating 0lig2 cells after brain injury. Brains from cyclopamine-treated (CYC) or vehicle-treated (Veh) mice injured $3 \mathrm{~d}$ before the animals were killed were used for immunofluorescence with an antibody to PCNA and antibodies to either 0lig2 or GFAP. All images taken at $10 \times$ magnification.

In contrast to cyclopamine-treated animals, animals receiving vehicle alone during the brain injury period demonstrated the stereotypical increase in Gli transactivation after injury (Figs. $1 C, D$; $4 A$, bottom inset). Animals receiving vehicle alone (Fig. $4 A$, corresponding Gli-Luc image in the inset; magnified PCNA staining in top inset) invariably exhibited a significant increase in the number of PCNA-positive cells compared with their cyclopamine-treated counterparts (Fig. 4B) or uninjured mice (data not shown). Quantification of proliferating cells in the injured cortex of vehicle- versus cyclopamine-treated mice showed a threefold reduction in cell proliferation (as measured by PCNA staining) after treating with cyclopamine $(p<0.01)$. These results suggest that reactive astrocyte-based activation of the SHH pathway in the injured cerebral cortex promotes cellular proliferation, the function of which remains to be fully explored.
Inhibition of the SHH-Gli axis reduces the proliferating Olig ${ }^{+}$progenitor pool responding to injury and the total number of Olig2 ${ }^{+}$cells in the injured cortex

Several studies have characterized the changes in the cellular composition and proliferative capacity of different cerebral cortical cell types after brain injury (Ludwin, 1984; Hampton et al., 2004; Zaidi et al., 2004; Tatsumi et al., 2005; Urrea et al., 2007). In many of these studies, the most commonly altered cell types after cerebral insults are astrocytes (which mostly undergo morphological changes and some proliferation), oligodendrocytes and their precursors (which proliferate), macrophage populations (which proliferate and secrete cytokines), and neurons (some of which die). Of all these cells, Olig2 ${ }^{+}$precursors appear to have the highest capacity for proliferation in vivo after brain injury (Zaidi et al., 2004; Buffo et al., 2005; Dimou et al., 2008).

To characterize a potential role for $\mathrm{SHH}$-regulated cell-fate-specific proliferation after cortical brain injury, we immunostained brains at $3 \mathrm{~d}$ after injury treated with vehicle alone and compared them with injured brains treated with cyclopamine for the proliferation marker PCNA and five cell-type-specific markers: GFAP (astrocytes), Olig2 (mostly oligodendrocyte precursors), Iba1 and CD11b (microglia/macrophages), and doublecortin (migrating neuroblasts). Uninjured brains displayed very few proliferating cells in the cortex (data not shown). Compared with vehicletreated, brain-injured controls, cyclopamine-treated, braininjured animals displayed a consistent and significant reduction in the number of proliferating Olig ${ }^{+}$cells $(45.5 \%$ proliferating Olig ${ }^{+}$cells in vehicle vs $12.91 \%$ in cyclopamine treated; $p=$ 0.0014 ) (Fig. 5). Consistent with the finding of a reduced percentage of cycling Olig ${ }^{+}$precursors in cyclopamine-treated animals, we also observed a statistically significant reduction in the overall number of Olig $2^{+}$cells in all $20 \times$ microscopic fields encompassing the injured cerebral cortex of cyclopamine-treated animals compared with injured animals treated with vehicle alone $(93 \pm$ 13 for vehicle alone; $54 \pm 6$ for cyclopamine treated; $p<0.001$ ). We also noted a modest but statistically significant decrease in the percentage of proliferating $\mathrm{GFAP}^{+}$reactive astrocytes after cyclopamine treatment during injury compared with vehicletreated animals $(4.5 \%$ proliferating GFAP cells receiving vehicle alone compared with $1.2 \%$ proliferating $\mathrm{GFAP}^{+}$cells in cyclopamine-treated, brain-injured animals). There was no significant increase in the overall number of $\mathrm{GFAP}^{+}$reactive astrocytes in vehicle compared with cyclopamine-treated injured brains ( $157 \pm 9.5$ for vehicle-treated injured brains vs $154 \pm 9.4$ for cyclopamine treatment) (Fig. 5). We propose that, unlike the injury-induced increase in Olig $2{ }^{+}$cell proliferation, in which the large percentage of cycling Olig $2^{+}$cells population likely contributes to an increase in the overall number of Olig2 ${ }^{+}$cells after cortical brain injury, the smaller percentage of $\mathrm{GFAP}^{+}$proliferating cells are not sufficient to increase the overall number of reactive astrocytes in a statistically significant manner. Of the two other cell types observed (Ibal ${ }^{+}$macrophages) and doublecortin- 
A

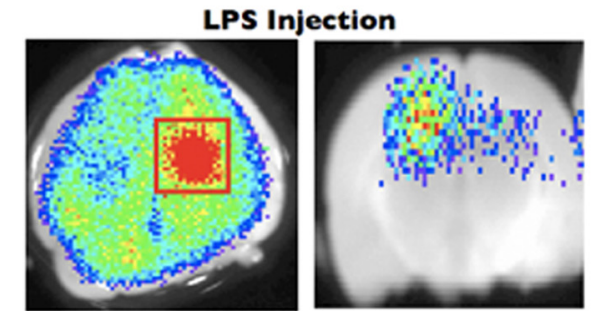

Saline Injection

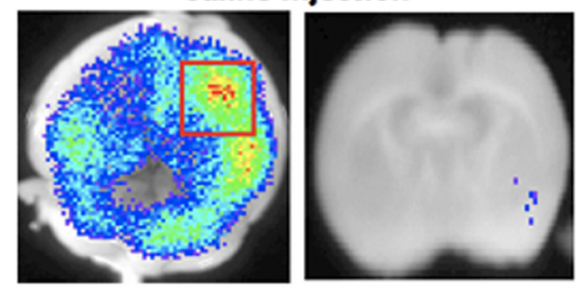

B

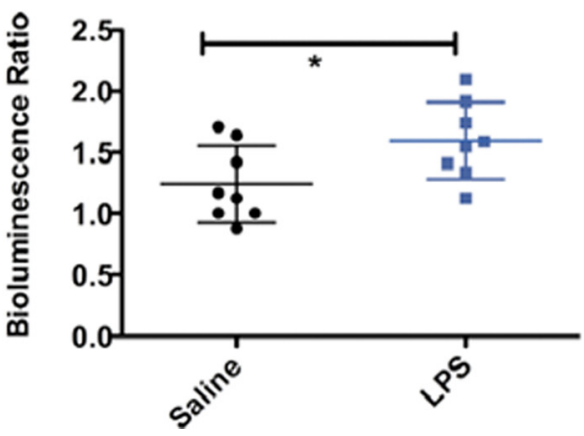

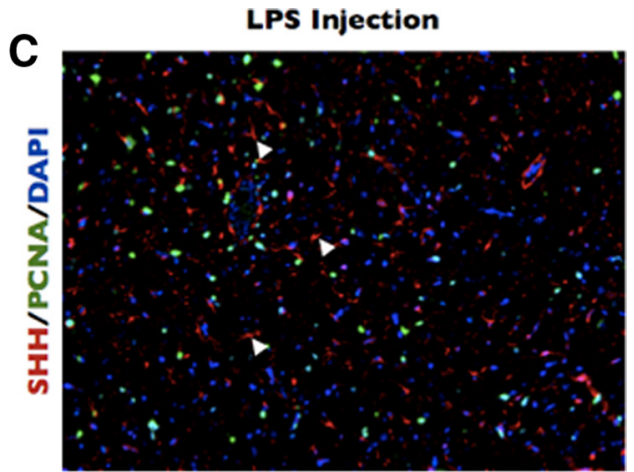

Saline Injection

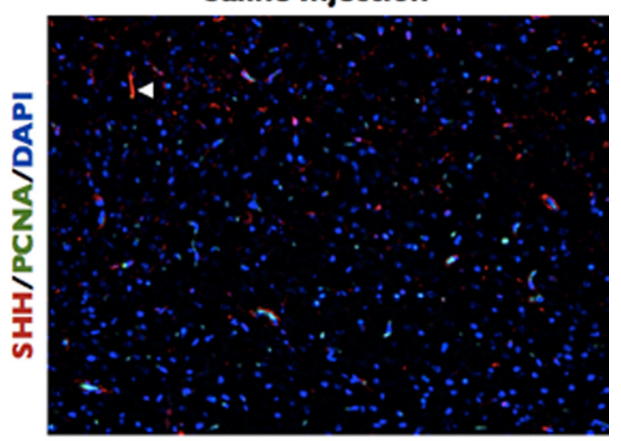

Figure 6. Intracerebral injection of LPS is capable of inducing Gli activation and SHH expression. Gli-Luc BLI of LPS-injected ( $\boldsymbol{A}$, top) or saline-injected $(\boldsymbol{A}$, bottom) mouse brains processed $3 \mathrm{~d}$ after injection. Red squares indicate the area of Gli activation. Left column is whole-brain BLl images, whereas right column is coronal slices made at the point of injury. Note that saline-injected brains also display increased Gli activation in the region of needle penetration. B, Column scatter graph showing the bioluminescence ratio of saline-injected (black circles) or LPS-injected (blue squares) brains. C, SHH, PCNA, and DAPI immunofluorescence staining for LPS-injected (top) or saline-injected (bottom) brains. Filled white arrowheads indicate SHH-positive cells. Images taken at 10X magnification. ${ }^{*} p<0.05$.

positive neuroblasts (data not shown), there were no significant differences in the number of proliferating cells or the number of overall cells in injured brains treated with vehicle alone or cyclopamine.

An inflammatory stimulus increases $\mathrm{SHH}^{+}$astrocytes and the Gli-Luc bioluminescence

Reactive gliosis can be a consequence of a local increase in intracerebral proinflammatory molecules in the presence or absence of mechanical brain injury. For example, proinflammatory cytokines (Giulian and Lachman, 1985; Giulian et al., 1988; Röhl et al., 2007), the bacterial cell-wall component LPS (Hauss-Wegrzyniak et al., 1998; Faulkner et al., 2004; Galic et al., 2008), and other inflammatory conditions (Little and O'Callagha, 2001) have been shown to induce astrogliosis within the brain parenchyma, thereby establishing an firm link between innate immune activation and reactive gliosis. Conversely, genetic ablation of proinflammatory cytokines and their receptors can result in markedly diminished reactive astrocyte levels or a delay in the onset of astrogliosis after brain injury (Herx and Yong, 2001; Penkowa et al., 2001; Lin et al., 2006) We asked whether astrocytic induction of $\mathrm{SHH}$ was restricted simply to our mechanical injury model of gliosis or whether a proinflammatory microenvironment (in the absence of severe mechanical injury) could activate the SHH-Gli axis. To answer this question, we stereotactically injected adult Gli-Luc mice with $1 \mu \mathrm{g}$ of LPS in $0.5 \mu \mathrm{l}$ of saline solution into the right frontoparietal cortex, whereas con- trols were injected with $0.5 \mu \mathrm{l}$ of saline alone. Consistent with previous reports of LPS-induced gliosis, we noticed a large increase in cells with astrocytic morphology in the LPSinjected cortex compared with the saline-injected controls. LPS-injected cortex abundantly expressed SHH in these cells (Fig. 6C, filled white arrows) compared with saline-injected controls (Fig. 6C, filled white arrows). Similar to our freeze-injury model, a large number of proliferating cells were seen after LPS injection but not in saline-injected controls (Fig. 6C). Gli bioluminescence was locally increased at the site of injection in both mice LPS-injected and control mice, although LPS injection produced considerably higher Gli activity than saline-injection alone (Fig. $6 \mathrm{~A}$, left panels are whole-brain BLI images, and right panels represent coronal section BLI images of injected mice). In addition, the bioluminescence ratio was significantly higher in the LPS-treated mice compared with their saline-injected counterparts (Fig. $6 B)(p<0.05)$. These experiments imply that the general mechanism of $\mathrm{SHH}$ activation within astrocytes involves the induction of inflammation.

Abrogation of $\mathrm{CD} 1 \mathrm{~b}^{+}$macrophages reduces reactive gliosis, SHH expression, and Gli responses to injury

Having confirmed the existence and potential role of the SHHGli axis in our acute brain injury model, we next wondered whether ablation of reactive astrocytes (the source of SHH during brain injury) would abolish $\mathrm{SHH}$ production and downstream Gli activation. 

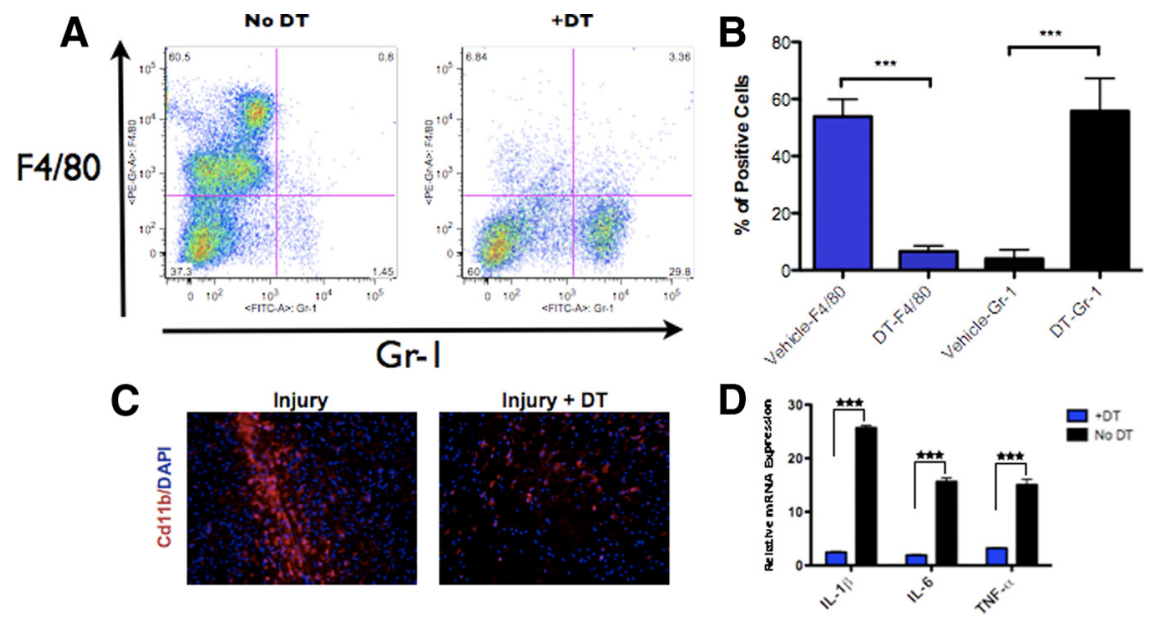

Figure 7. Treating CD11b-DTR mice with DT reduces the total number of peritoneal and brain macrophages and induces a marked reduction in cytokine production after brain injury. $\boldsymbol{A}$, Representative flow cytometry plot of cells obtained from peritoneal lavage of injured CD11b-DTR mice treated with DT or vehicle alone after staining for F4/80 (macrophage marker) and Gr-1 (neutrophil marker). There is a reduction in F4/80-positive cells (macrophages), as quantified in $\boldsymbol{B}\left({ }^{* *} p<0.001\right)$. C, Immunofluorescence staining for CD11b and DAPI in injured brains from CD11b-DTR mice (3 d after injury) treated with or without DT. D, Quantitative RT-PCR analysis of injured brains ( 3 d after injury) from mice treated with DT or vehicle alone $\left({ }^{* * *} p<0.001\right)$. Images in $C$ taken at $20 \times$ magnification.

We reasoned that we could abolish reactive gliosis by removing the proinflammatory signals upstream of reactive astrocyte formation (Herrmann et al., 2008). To accomplish this, we crossed the CD11b-DTR mouse (Duffield et al., 2005) to our Gli-Luc mouse. In the CD11b-DTR model, administration of $\mathrm{DT}$ ablates $\mathrm{CD} 11 \mathrm{~b}^{+}$macrophage populations (including peripheral macrophages and microglia), which are the putative sources of reactive astrocyte-inducing cytokines. We injected CD11bDTR/Gli-Luc heterozygous mice with $25 \mathrm{ng} / \mathrm{g}$ DT $1 \mathrm{~d}$ before injury and then daily for a total of four doses before the animals were killed $3 \mathrm{~d}$ after injury. FACS analysis of peritoneal F4/80 ${ }^{+}$ macrophages and brain CD11b immunostaining of CD11bDTR/Gli-Luc mice treated with DT showed significant reductions macrophage populations compared with vehicle-treated mice and wild-type controls (Fig. 7A,B). Proinflammatory cytokine levels in DT-injected CD11b-DTR/Gli-Luc mice were markedly lower compared with controls as determined by quantitative PCR (Fig. 7D) $(p<0.001$ for levels of IL-1 $\beta$, IL-6, and TNF- $\alpha$ ).

We next examined reactive gliosis and $\mathrm{SHH}$ production from astrocytes after macrophage depletion. All injury-induced astrocyte populations were substantially reduced, SHH expression was virtually absent, and local Gli-Luc bioluminescence was severely diminished in DT-treated CD11b-DTR/Gli-Luc mice (Fig. 8 A$C)$. In contrast to DT-treated mice, vehicle-treated mice responded to injury with characteristic increases in reactive astrocytes at the injury site, an upregulation of $\mathrm{SHH}$ in $\mathrm{GFAP}^{+}$ astrocytes, and a local increase in Gli-Luc BLI at the site of injury (Fig. $8 A-C$ ). Consistent with a role for inflammatory cytokines in the induction of reactive gliosis and $\mathrm{SHH}$ production within these astrocytes, injection of IL- $1 \beta$ (10 ng in $1 \mu \mathrm{l}$ of water) at the time of injury partially rescued reactive gliosis and Gli-Luc BLI output after treatment of CD11b-DTR/Gli-Luc mice with DT (Fig. $8 A-C$ ). These experiments point to a role for inflammationinducing macrophage populations in the pathogenesis of reactive gliosis and SHH-Gli activation.

\section{Discussion}

Brain injuries, including traumatic blunt injury, penetrating brain injury, and neurodegenerative and autoimmune brain together comprise a large and devastating group of human diseases (Maas et al., 2008). The mammalian brain engages in a self-limited program of injury-initiated cell proliferation and understanding the physiologic factors that promote cell proliferation during brain injury could be helpful, because some of these same factors may be used as therapeutic agents to counteract the loss of cells in the setting of a variety of brain injuries.

The pleiotropic morphogen and mitogen $\mathrm{SHH}$ is one factor that may contribute to brain-injury-induced proliferation. Increased expression of $\mathrm{SHH}$ has been observed during injury to adult tissue, including brain ischemia (Androutsellis-Theotokis et al., 2006), multiple sclerosis (Mastronardi et al., 2004; Seifert et al., 2005; Wang et al., 2008), and even during ischemic-reperfusion injury in muscular tissue and the kidney.

\section{SHH is expressed in reactive astrocytes after brain injury}

We set out to investigate four important questions relating to the presence and function of SHH-Gli axis in a commonly used model of focal brain injury: (1) whether SHH was expressed during brain injury; (2) whether its cellular source could be identified; (3) whether the precise population of cells whose proliferation was regulated by $\mathrm{SHH}$ could be identified; and (4) whether we could describe some physiologic mechanisms upstream of $\mathrm{SHH}$ activation.

As we showed previously in a mouse model of glioblastoma, reactive astrocytes can produce significant amounts of $\mathrm{SHH}$ and activate the downstream Gli signaling (Becher et al., 2008). Several groups have now shown that astrocytes can in fact be a source of SHH production (Sahir et al., 2004; Jiao and Chen, 2008). The role of reactive astrocytes that are formed in response to CNS injury has been controversial, with some groups arguing that reactive astrocytosis can impede neurogenesis and axonal repair (Larsson et al., 2004; Silver and Miller, 2004), whereas others have shown that reactive and cytokine-stimulated astrocytes are able to restrict the volume of injured tissue by promoting cell proliferation, generating a number of growth factors, and by providing structural support to the damaged CNS tissue (Bush et al., 1999; Liberto et al., 2004; Myer et al., 2006; Li et al., 2008). Our current study shows that a gliosis-generating injury within the mouse forebrain induces $\mathrm{SHH}$ production from astrocytes and that $\mathrm{SHH}$ likely instructs protective signals to the injured brain by increasing the proliferation and total number of Olig ${ }^{+}$lineage cells. Although reactive astrocytes may not serve universally protective functions during these injuries, it is possible that astrocytes are a part of a complex response to forebrain injury and that they may have regenerative functions in addition to the inhibitory ones described above. 

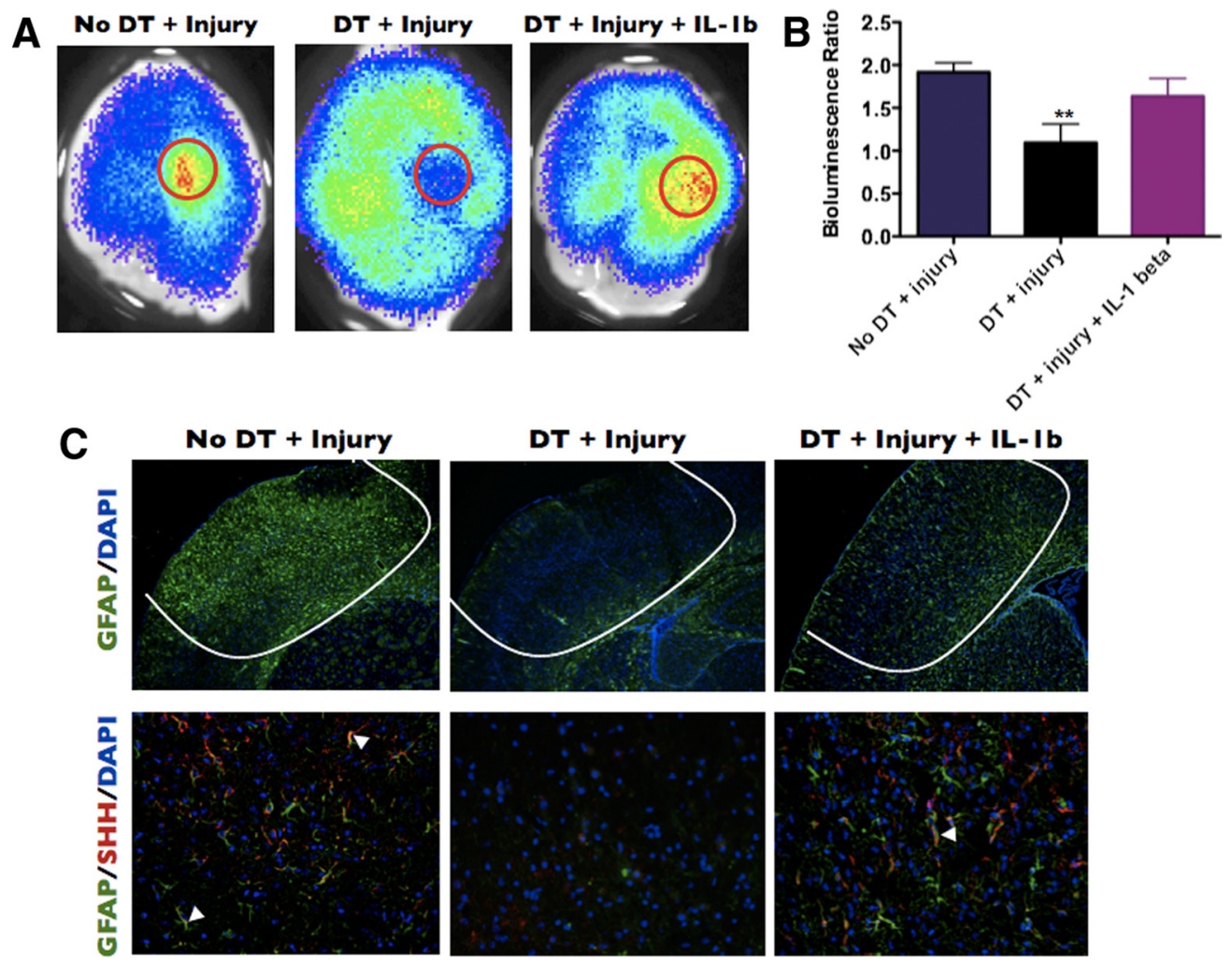

Figure 8. Macrophage depletion reduces Gli activation, astroglial activation, and SHH expression in brain-injured mice. A, CD11b-DTR mice injected with vehicle, DT, or with DT plus an intracerebral injection of mouse IL-1 $\beta$ were killed $3 \mathrm{~d}$ after cortical freeze injury, and BLl images were obtained. $\boldsymbol{B}$, Quantification of the bioluminescence ratio in $\boldsymbol{A}$. $\boldsymbol{C}$, Immunofluorescence of a brain from the same groups as in $\boldsymbol{A}$ stained for either GFAP and DAPI (top row) or GFAP, SHH, and DAPI (bottom row). $\boldsymbol{C}$, Top row, $5 \times$ magnification; bottom row, $20 \times$ magnification. ${ }^{* *} p<0.01$.

SHH induces proliferation of Olig ${ }^{+}$cells after brain injury We show that $\mathrm{SHH}$ expression in the context of a cortical brain injury appears to recapitulate part of the function of $\mathrm{SHH}$ during telencephalic development, which is to increase the proliferation and number of Olig2 ${ }^{+}$cells (Nery et al., 2001; Tekki-Kessaris et al., 2001). The function of these newly generated SHH-dependent Olig2 ${ }^{+}$cells and their capacity to mature into functional oligodendrocytes and remyelinate locally injured axons is a topic we want to explore in subsequent studies using more extensive injury models. However, it is worth noting that there is emerging evidence to suggest that proliferating Olig ${ }^{+}$cells in the injured mammalian forebrain can go on to form mature, myelinating oligodendrocytes (Ligon et al., 2006; Dimou et al., 2008). We hypothesize, therefore, that SHH pathway reactivation may be responsible for remyelination in the adult brain by inducing proliferation of Olig2 ${ }^{+}$ precursors that may then contribute to the myelination of injured axons. In contrast to the existing paradigms of Olig2 function, some investigators have now linked Olig2 to the development of astroglia in the adult brain (Chen et al., 2008); however, in our studies, we rarely observed Olig2/GFAP double-positive cells after injury.

\section{Proinflammatory signals are necessary for astrocyte formation and $\mathrm{SHH}$ expression}

Our study identifies inflammatory stimuli from $\mathrm{CD} 11 \mathrm{~b}^{+}$cells as a necessary factor in the induction of reactive gliosis and $\mathrm{SHH}$ production in our model of brain injury. As with reactive astrocytes themselves, proinflammatory components of the innate immune system are often viewed as both potentially regenerative and destructive in the context of brain injury (Lalancette-Hébert et al., 2007; Das and Basu, 2008). The real role of innate immunity during brain injury is likely to be multifaceted and context dependent. It is possible that the early stages of inflammation can be neuroprotective by activating mechanisms (some of which are astrocyte dependent) that induce cell proliferation and repair the injured blood-brain barrier. However, as in multiple sclerosis, failure to restrict such inflammation might ultimately lead to widespread cell death. One argument in favor of a positive role for proinflammatory signals during acute brain injury is that attempts to treat such injuries with a variety of anti-inflammatory agents have been mostly unsuccessful and even potentially detrimental (Alderson and Roberts, 2005), suggesting that inflammation may have positive contributions to recovery from brain trauma, at least in the acute setting.

For the first time, we establish a link in vivo between proinflammatory signals and the expression of $\mathrm{SHH}$ expression during brain injury. In vitro, cytokine-treated astrocytes induce expression of SHH mRNA $3 \mathrm{~d}$ after exposure to IL- $1 \beta$, TNF- $\alpha$, and interferon- $\gamma$ (Falsig et al., 2006). Many proinflammatory signals activate the nuclear factor $\kappa \mathrm{B}(\mathrm{NF} \kappa \mathrm{B})$ transcription factor pathway, and a recent study describes $\mathrm{SHH}$ as a direct transcriptional target of NF $\kappa \mathrm{B}$ (Kasperczyk et al., 2009). These findings create the intriguing possibility that cytokine exposure to astrocytes in vivo directly activates the NF $\kappa \mathrm{B}$ pathway, which then induces $\mathrm{SHH}$ transcription in these cells. The potential involvement of the $\mathrm{NF} \kappa \mathrm{B}$ pathway in injury-induced astrocyte-based $\mathrm{SHH}$ production requires additional investigation. In our model of injury, injection of IL- $1 \beta$ into the site of injury during macrophage depletion rescues reactive gliosis and the activation of the SHH-Gli pathway. These results suggests that astrocyte-based SHH production is dependent not only on the cellular source of inflam- 
mation (microglia, macrophages, and astrocytes) but also on the proinflammatory cytokines that they elaborate.

Our work introduces the activation of the SHH-Gli axis in reactive astrocytes formed after mechanical brain injury and delineates the potential role of in vivo inflammatory signals in the activation of these reactive astrocytes and in the activation of the SHH pathway. These data add to a growing body of literature that suggests that the role of reactive astrocytes and proinflammatory signals is not merely destructive after brain injury but that additional inquiries need to be made about potential contexts in which inflammation-induced events, such as reactive gliosis, serve regenerative roles after brain injury.

\section{References}

Ahn S, Joyner AL (2005) In vivo analysis of quiescent adult neural stem cells responding to Sonic hedgehog. Nature 437:894-897.

Alderson P, Roberts I (2005) Corticosteroids for acute traumatic brain injury. Cochrane Database Syst Rev 2005:CD000196.

Androutsellis-Theotokis A, Leker RR, Soldner F, Hoeppner DJ, Ravin R, Poser SW, Rueger MA, Bae SK, Kittappa R, McKay RD (2006) Notch signalling regulates stem cell numbers in vitro and in vivo. Nature 442:823-826.

Becher OJ, Hambardzumyan D, Fomchenko EI, Momota H, Mainwaring L, Bleau AM, Katz AM, Edgar M, Kenney AM, Cordon-Cardo C, Blasberg RG, Holland EC (2008) Gli activity correlates with tumor grade in plateletderived growth factor-induced gliomas. Cancer Res 68:2241-2249.

Buffo A, Vosko MR, Ertürk D, Hamann GF, Jucker M, Rowitch D, Götz M (2005) Expression pattern of the transcription factor Olig2 in response to brain injuries: implications for neuronal repair. Proc Natl Acad Sci U S A 102:18183-18188.

Bush TG, Puvanachandra N, Horner CH, Polito A, Ostenfeld T, Svendsen CN, Mucke L, Johnson MH, Sofroniew MV (1999) Leukocyte infiltration, neuronal degeneration, and neurite outgrowth after ablation of scarforming, reactive astrocytes in adult transgenic mice. Neuron 23:297-308.

Chen Y, Miles DK, Hoang T, Shi J, Hurlock E, Kernie SG, Lu QR (2008) The basic helix-loop-helix transcription factor olig2 is critical for reactive astrocyte proliferation after cortical injury. J Neurosci 28:10983-10989.

Das S, Basu A (2008) Inflammation: a new candidate in modulating adult neurogenesis. J Neurosci Res 86:1199-1208.

Dimou L, Simon C, Kirchhoff F, Takebayashi H, Götz M (2008) Progeny of Olig2-expressing progenitors in the gray and white matter of the adult mouse cerebral cortex. J Neurosci 28:10434-10442.

Duffield JS, Forbes SJ, Constandinou CM, Clay S, Partolina M, Vuthoori S, Wu S, Lang R, Iredale JP (2005) Selective depletion of macrophages reveals distinct, opposing roles during liver injury and repair. J Clin Invest 115:56-65.

Eggenschwiler JT, Anderson KV (2000) Dorsal and lateral fates in the mouse neural tube require the cell-autonomous activity of the open brain gene. Dev Biol 227:648-660.

Falsig J, Pörzgen P, Lund S, Schrattenholz A, Leist M (2006) The inflammatory transcriptome of reactive murine astrocytes and implications for their innate immune function. J Neurochem 96:893-907.

Faulkner JR, Herrmann JE, Woo MJ, Tansey KE, Doan NB, Sofroniew MV (2004) Reactive astrocytes protect tissue and preserve function after spinal cord injury. J Neurosci 24:2143-2155.

Galic MA, Riazi K, Heida JG, Mouihate A, Fournier NM, Spencer SJ, Kalynchuk LE, Teskey GC, Pittman QJ (2008) Postnatal inflammation increases seizure susceptibility in adult rats. J Neurosci 28:6904-6913.

Giulian D, Lachman LB (1985) Interleukin-1 stimulation of astroglial proliferation after brain injury. Science 228:497-499.

Giulian D, Woodward J, Young DG, Krebs JF, Lachman LB (1988) Interleukin-1 injected into mammalian brain stimulates astrogliosis and neovascularization. J Neurosci 8:2485-2490.

Hampton DW, Rhodes KE, Zhao C, Franklin RJ, Fawcett JW (2004) The responses of oligodendrocyte precursor cells, astrocytes and microglia to a cortical stab injury, in the brain. Neuroscience 127:813-820.

Hauss-Wegrzyniak B, Dobrzanski P, Stoehr JD, Wenk GL (1998) Chronic neuroinflammation in rats reproduces components of the neurobiology of Alzheimer's disease. Brain Res 780:294-303.

Herrmann JE, Imura T, Song B, Qi J, Ao Y, Nguyen TK, Korsak RA, Takeda K,
Akira S, Sofroniew MV (2008) STAT3 is a critical regulator of astrogliosis and scar formation after spinal cord injury. J Neurosci 28:7231-7243.

Herx LM, Yong VW (2001) Interleukin-1 beta is required for the early evolution of reactive astrogliosis following CNS lesion. J Neuropathol Exp Neurol 60:961-971.

Höke A, Silver J (1994) Heterogeneity among astrocytes in reactive gliosis. Perspect Dev Neurobiol 2:269-274.

Incardona JP, Gaffield W, Kapur RP, Roelink H (1998) The teratogenic Veratrum alkaloid cyclopamine inhibits sonic hedgehog signal transduction. Development 125:3553-3562.

Jiao J, Chen DF (2008) Induction of neurogenesis in nonconventional neurogenic regions of the adult CNS by niche astrocyte-produced signals. Stem Cells 26:1221-1230.

Kasperczyk H, Baumann B, Debatin KM, Fulda S (2009) Characterization of sonic hedgehog as a novel NF- $\kappa \mathrm{B}$ target gene that promotes NF- $\kappa \mathrm{B}$ mediated apoptosis resistance and tumor growth in vivo. FASEB J 23:21-33.

Lalancette-Hébert M, Gowing G, Simard A, Weng YC, Kriz J (2007) Selective ablation of proliferating microglial cells exacerbates ischemic injury in the brain. J Neurosci 27:2596-2605.

Larsson A, Wilhelmsson U, Pekna M, Pekny M (2004) Increased cell proliferation and neurogenesis in the hippocampal dentate gyrus of old $\operatorname{GFAP}(-/-) \operatorname{Vim}(-/-)$ mice. Neurochem Res 29:2069-2073.

Li L, Lundkvist A, Andersson D, Wilhelmsson U, Nagai N, Pardo AC, Nodin C, Ståhlberg A, Aprico K, Larsson K, Yabe T, Moons L, Fotheringham A, Davies I, Carmeliet P, Schwartz JP, Pekna M, Kubista M, Blomstrand F, Maragakis N, Nilsson M, Pekny M (2008) Protective role of reactive astrocytes in brain ischemia. J Cereb Blood Flow Metab 28:468-481.

Liberto CM, Albrecht PJ, Herx LM, Yong VW, Levison SW (2004) Proregenerative properties of cytokine-activated astrocytes. J Neurochem 89:1092-1100.

Ligon KL, Kesari S, Kitada M, Sun T, Arnett HA, Alberta JA, Anderson DJ, Stiles CD, Rowitch DH (2006) Development of NG2 neural progenitor cells requires Olig gene function. Proc Natl Acad Sci U S A 103:7853-7858.

Lin HW, Basu A, Druckman C, Cicchese M, Krady JK, Levison SW (2006) Astrogliosis is delayed in type 1 interleukin-1 receptor-null mice following a penetrating brain injury. J Neuroinflammation 3:15.

Little AR, O'Callagha JP (2001) Astrogliosis in the adult and developing CNS: is there a role for proinflammatory cytokines? Neurotoxicology 22:607-618.

Ludwin SK (1984) Proliferation of mature oligodendrocytes after trauma to the central nervous system. Nature 308:274-275.

Maas AI, Stocchetti N, Bullock R (2008) Moderate and severe traumatic brain injury in adults. Lancet Neurol 7:728-741.

Mastronardi FG, Min W, Wang H, Winer S, Dosch M, Boggs JM, Moscarello MA (2004) Attenuation of experimental autoimmune encephalomyelitis and nonimmune demyelination by IFN-beta plus vitamin B12: treatment to modify notch-1/sonic hedgehog balance. J Immunol 172:6418-6426.

Myer DJ, Gurkoff GG, Lee SM, Hovda DA, Sofroniew MV (2006) Essential protective roles of reactive astrocytes in traumatic brain injury. Brain 129:2761-2772.

Nery S, Wichterle H, Fishell G (2001) Sonic hedgehog contributes to oligodendrocyte specification in the mammalian forebrain. Development 128:527-540.

Palma V, Lim DA, Dahmane N, Sánchez P, Brionne TC, Herzberg CD, Gitton Y, Carleton A, Alvarez-Buylla A, Ruiz i Altaba A (2005) Sonic hedgehog controls stem cell behavior in the postnatal and adult brain. Development 132:335-344.

Penkowa M, Molinero A, Carrasco J, Hidalgo J (2001) Interleukin-6 deficiency reduces the brain inflammatory response and increases oxidative stress and neurodegeneration after kainic acid-induced seizures. Neuroscience 102:805-818.

Raghupathi R, Graham DI, McIntosh TK (2000) Apoptosis after traumatic brain injury. J Neurotrauma 17:927-938.

Röhl C, Lucius R, Sievers J (2007) The effect of activated microglia on astrogliosis parameters in astrocyte cultures. Brain Res 1129:43-52.

Russell MC, Cowan RG, Harman RM, Walker AL, Quirk SM (2007) The hedgehog signaling pathway in the mouse ovary. Biol Reprod 77:226-236.

Sahir N, Evrard P, Gressens P (2004) Caffeine induces sonic hedgehog gene 
expression in cultured astrocytes and neurons. J Mol Neurosci 24:201-205.

Sasaki H, Hui C, Nakafuku M, Kondoh H (1997) A binding site for Gli proteins is essential for HNF-3beta floor plate enhancer activity in transgenics and can respond to Shh in vitro. Development 124:1313-1322.

Seifert T, Bauer J, Weissert R, Fazekas F, Storch MK (2005) Differential expression of sonic hedgehog immunoreactivity during lesion evolution in autoimmune encephalomyelitis. J Neuropathol Exp Neurol 64:404-411.

Silver J, Miller JH (2004) Regeneration beyond the glial scar. Nat Rev Neurosci 5:146-156.

Stone DM, Hynes M, Armanini M, Swanson TA, Gu Q, Johnson RL, Scott MP, Pennica D, Goddard A, Phillips H, Noll M, Hooper JE, de Sauvage F, Rosenthal A (1996) The tumour-suppressor gene patched encodes a candidate receptor for Sonic hedgehog. Nature 384:129-134.

Sun L, Lee J, Fine HA (2004) Neuronally expressed stem cell factor induces neural stem cell migration to areas of brain injury. J Clin Invest 113:1364-1374.

Talbott JF, Loy DN, Liu Y, Qiu MS, Bunge MB, Rao MS, Whittemore SR (2005) Endogenous Nkx2.2+/Olig2+ oligodendrocyte precursor cells fail to remyelinate the demyelinated adult rat spinal cord in the absence of astrocytes. Exp Neurol 192:11-24.
Tatsumi K, Haga S, Matsuyoshi H, Inoue M, Manabe T, Makinodan M, Wanaka A (2005) Characterization of cells with proliferative activity after a brain injury. Neurochem Int 46:381-389.

Tekki-Kessaris N, Woodruff R, Hall AC, Gaffield W, Kimura S, Stiles CD, Rowitch DH, Richardson WD (2001) Hedgehog-dependent oligodendrocyte lineage specification in the telencephalon. Development 128:2545-2554.

Urrea C, Castellanos DA, Sagen J, Tsoulfas P, Bramlett HM, Dietrich WD (2007) Widespread cellular proliferation and focal neurogenesis after traumatic brain injury in the rat. Restor Neurol Neurosci 25:65-76.

Wang Y, Imitola J, Rasmussen S, O'Connor KC, Khoury SJ (2008) Paradoxical dysregulation of the neural stem cell pathway sonic hedgehog-Gli1 in autoimmune encephalomyelitis and multiple sclerosis. Ann Neurol 64:417-427.

White RE, Jakeman LB (2008) Don't fence me in: harnessing the beneficial roles of astrocytes for spinal cord repair. Restor Neurol Neurosci 26:197-214.

Zaidi AU, Bessert DA, Ong JE, Xu H, Barks JD, Silverstein FS, Skoff RP (2004) New oligodendrocytes are generated after neonatal hypoxicischemic brain injury in rodents. Glia 46:380-390. 